
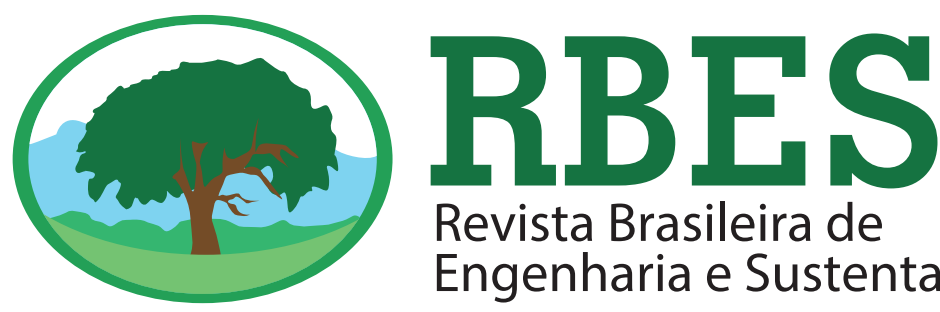

\title{
O DEBATE E A COMPREENSÃO DA REALIDADE AGRÁRIA DENTRO DO ESTÁGIO INTERDISCIPLINAR DE VIVÊNCIA EM ASSENTAMENTOS DA ZONA SUL DO RIO GRANDE DO SUL
}

\author{
MALDANER, V. ${ }^{1}$; PEREIRA, N. D. A. ${ }^{2}$; GADOTTI, G. I. ${ }^{3}$; DALFOLO, R. ${ }^{4}$; QUADRO, M. S. ${ }^{5}$; NETO, M. B. ${ }^{6}$ \\ ${ }^{1}$ Acadêmica de Engenharia Agrícola, Universidade Federal de Pelotas \\ ${ }^{2}$ Acadêmica de Ciências Sociais, Universidade Federal de Pelotas \\ ${ }^{3}$ Professora adjunta Centro de Engenharias, Universidade Federal de Pelotas \\ ${ }^{4}$ Técnico EMATER/RS-ASCAR \\ ${ }^{5}$ Professor adjunto Centro de Engenharias, Universidade Federal de Pelotas \\ ${ }^{6}$ Engenheira Hídrica
}

Palavras-chave: comunidades rurais, agricultores, transformações sociais.

\section{Resumo}

O Estágio Interdisciplinar de Vivência em Assentamentos na Zona Sul do Rio Grande do Sul da Universidade Federal de Pelotas vem com a proposta de trazer à tona a realidade rural para os alunos ingressantes no projeto e que desta forma consigam enxergar os verdadeiros problemas dentro desses assentamentos, exercendo seu conhecimento acadêmico nas necessidades dos agricultores. Os objetivos gerais do estágio consistem em proporcionar a integração dos estudantes em condições distintas, estimular os alunos a promover ações que possibilitem a melhoria de vida das famílias envolvidas e assim influenciar nas transformações sociais. 0 presente trabalho foi realizado no Assentamento "Abrindo Fronteiras", localizado no município de Hulha Negra onde foram realizados levantamentos e a interpretação de dados para obter um diagnóstico socioeconômico e ambiental do assentamento, e validado a campo através de questionamentos. Em síntese, pode-se concluir que o estágio é uma troca, visando a melhorar a vida dos assentados, mas também proporcionar uma formação mais completa aos alunos participantes, formando profissionais experientes, qualificados e preocupados com a comunidade rural.

\section{DEBATE AND UNDERSTANDING OF AGRARIAN REALITY INSIDE OF A INTERDISCIPLINARY INTERNSHIP OF EXPERIENCE IN SETTLEMENTS FROM THE SOUTH OF RIO GRANDE DO SUL}

Keywords: rural communities, farmers, social transformations.

\begin{abstract}
The Federal University of Pelotas Interdisciplinary internship experience project, in settlements in the Southern region of Rio Grande do Sul, comes with the proposal to bring the rural reality to the students and in this way can see the real problems within these settlements, exercising their academic knowledge on the needs of farmers. The general objectives of the internship project are to provide the integration of students in different conditions, to stimulate students to promote actions that improve the lives of the families involved and thus influence social transformations. The present study was carried out in the "Abrindo Fronteiras" settlement located in Hulha NegraCounty, where surveys and data interpretation were performed to obtain a socio-economic and environmental diagnosis of the settlement, and validated in the field through questioning. In short, it was concluded that the internship is an exchange, aiming to improve the lives of the farmers, but also to provide a more complete training to the students, training professionals who are experienced, qualified, and concerned with the rural community.
\end{abstract}




\section{INTRODUÇÃO}

A reforma agrária surgiu no Brasil buscando a divisão igualitária de terras. Em 1970 com a criação do Instituto Nacional de Colonização e Reforma Agrária, mais conhecido como INCRA, órgão responsável pelo ordenamento fundiário nacional, surge o conceito de assentamento rural, que é baseado no princípio do máximo aproveitamento da terra. Com isso, onde antes havia um grande imóvel rural pertencente a um único proprietário, fez-se a distribuição de pequenos lotes que unidos passaram a formar um assentamento rural (INCRA, 2016).

Uma comunidade rural composta de áreas de moradia e unidades produtivas necessita de serviços básicos de todas as áreas do governo, como investimentos na educação, saúde e construção de estradas, além de auxílios em créditos e assistência técnica. $\mathrm{O}$ assentamento rural possui também áreas comunitárias que são destinadas à criação de igrejas, sedes de associaçôes e salóes comunitários. Para receber esses auxílios os trabalhadores que vivem como assentados rurais comprometem-se em fixar moradia no lote recebido e explorar a terra com máo de obra familiar de modo a sustentar a segurança alimentar da família e contribuir com o excedente para erradicar a falta de comida. Segundo o INCRA (2016), enquanto o lote não é escriturado a terra recebida não pode ser vendida, alugada, arrendada ou emprestada a particulares.

A UNESCO define analfabetismo funcional como a situação de instrução de alguém que assina o próprio nome ou é capaz de fazer cálculos simples e ler palavras e frases isoladas, mas não é capaz de interpretar o sentido dos textos, não é capaz de usar a leitura e a escrita para seu desenvolvimento pessoal, nem para fazer frente as suas demandas sociais (LORENZO, 2007).

O estado do Rio Grande do Sul foi um grande adepto a essa distribuiçáo de terras baseada no modelo de assentamento, e também buscou conceber infraestrutura e crédito aos agricultores. É muito importante o envolvimento dos estados e dos municípios para a melhoria dessas terras e na vida dessas pessoas que ali habitam, pois, as terras concebidas são desprovidas de infraestrutura e esses assentados não possuem condiçôes de fazer por si as melhorias necessárias. Na zona sul do estado do Rio Grande do Sul há um grande número de propriedades exploradas dessa forma, com muitos assentamentos introduzidos no município de Hulha Negra, quando em 1989 instalam-se na região famílias oriundas do norte do estado, organizada pelo Movimento dos Trabalhadores Sem Terra (MST).

Buscando a interdisciplinaridade entre prática e teoria, surge o Projeto de Vivência em Assentamentos da Zona Sul do Rio Grande do Sul, promovido pela Universidade Federal de Pelotas através de apoio financeiro do Programa de Extensão Universitária PROEXT do Ministério da Educação e contribuição das unidades de gestão pública dos municípios da regiāo registrado pelo número 51131016. O Estágio de Vivência é um período de tempo no qual estudantes universitários convivem com comunidades rurais e assentamentos e pretende discutir a necessidade de uma profunda reorientação dos padróes de organização socioeconômica da agricultura para alcançar sua sustentabilidade, caminhando assim, para a produção de alimentos de melhor qualidade biológica, livres de agrotóxicos de forma ambientalmente mais amigável (CAPORAL, 2002).

Menezes (2004) retrata que o trabalho de campo além de ser um importante momento de coleta de informação e integração com o objeto de pesquisa, permite múltiplos aprendizados e é também um espaço gerador de tensões e questionamentos. Dessa maneira são revelados entraves das proposiçóes podendo gerar uma reformulação da análise dos dados.

A atividade de vivência tem como objetivo trazer à tona a realidade de subsistência dos assentamentos, utilizando o conhecimento dos acadêmicos a fim de buscar soluçóes para melhoria de vida dos assentados e da terra onde habitam. Além disto, propicia a experiência de conviver com uma realidade diferente da sua, trabalharem com alunos de outras áreas e ter contato com gestores estaduais e municipais, formando não só profissionais competentes na sua formação, mas profissionais ligados a todos os setores da sociedade de forma social, política, econômica e cultural. Dessa maneira como consequência forma um profissional mais ligado à sociedade, comprometido com as reais demandas e qualificado para intervir e solucionar os 
problemas da realidade agrária brasileira.

O desenvolvimento sustentável no meio rural é um fator almejado, pois o acesso à terra se reverte em transformaçôes econômica, social e política que atingem a população beneficiária. Desse modo, busca-se a mensuração do avanço sustentável e suas repercussôes. Com o intuito de auxiliar na busca por respostas, o presente artigo tem como objetivo o levantamento e interpretação de dados para obter um diagnóstico socioeconômico e ambiental do Assentamento "Abrindo Fronteiras", localizado no Sul do Rio Grande do Sul, através do Projeto Interdisciplinar de Vivência em Assentamentos da Zona Sul do Rio Grande do Sul.

\section{MATERIAL E MÉTODOS}

A área de estudo do presente trabalho foi o assentamento rural "Abrindo Fronteiras", situado no município de Hulha Negra, o qual faz parte da Associação dos Municípios da Zona Sul do Rio Grande do Sul.

A primeira etapa do projeto foi a criação de canais de divulgação, com o intuito de promover o estágio para toda a Universidade Federal de Pelotas - UFPel. Como um dos objetivos do Projeto de Estágio Interdisciplinar de Vivência em Assentamentos da Zona Sul do Rio Grande do Sul é universalizar o estágio para toda a Universidade é indispensável a divulgaçáo do projeto para que mais tarde outros alunos possam vir a participar do estágio de vivência nos assentamentos. Terminado isto, foi realizado o contato com os atores, junto aos municípios e aos representantes dos assentamentos, com a finalidade de elaborar os delineamentos do estágio de vivência junto aos assentados.

Para avaliação dos aspectos sociais e econômicos do assentamento foi utilizado o acesso aos dados do Sistema Integrado de Gestão Rural da ATESRS (SIGRA), disponibilizado pela EMATER-RS e validado a campo através de questionamentos. $\mathrm{O}$ banco de dados continha número de pessoas assentadas, idade, nível de escolaridade, gênero, mão de obra, produção vegetal e animal, tipo de moradia, acesso à água potável e saneamento básico. Através de visitas teve-se a oportunidade de conhecer o local e as famílias que ali habitam e assim iniciar o processo de identificação da realidade desse grupo de pessoas.

Com o período de vivência e a identificação dos problemas, a elaboração de ideias para melhorias na comunidade vem a momento de pós-vivência onde os alunos voltam ao local e implantam as ideias desenvolvidas para beneficiar os agricultores. Uma preocupação constante foi a coleta de amostras de água dos locais, levadas em seguida para o Laboratório de Química Ambiental do Centro de Engenharias da Universidade Federal de Pelotas para realizar análise de qualidade da água.

Feito isso, o projeto passa a ser avaliado verificandose tudo que foi executado até o presente. Os alunos participantes passaram por uma avaliação para que posteriormente possam elaborar trabalhos acadêmicos e apresentá-los em um Workshop com os trabalhos desenvolvidos na área para a universidade e a comunidade. Concluindo a última etapa é a criado um núcleo de assistência técnica para assessorar esses pequenos agricultores nas suas necessidades do dia a dia.

\section{RESULTADOS E DISCUSSÃO}

O assentamento é formado por aproximadamente 700 pessoas, conforme conta no banco de dados do SIGRA. As famílias em sua maioria são pequenas e constituídas de um ou dois elementos com predominância de pessoas adultas, com idades entre 25 e 60 anos. Relacionando o número total de pessoas, foi considerada alta a populaçáo idosa no assentamento e, consequentemente, a maioria é aposentada. Isso mostra o aumento do êxito rural e a baixa expectativa de sucessáo no campo, além da reduçáo do potencial de força de trabalho, que diminui conforme o aumento da idade.

Contrariando a realidade brasileira, que indica que a população feminina é maioria, com a taxa de 51,03\%, segundo dados do censo demográfico de 2010, do Instituto Brasileiro de Geografia e Estatística - IBGE, a predominância no assentamento "Abrindo Fronteiras" é de homens em quase 5\% de diferença, como se observa na Figura 1. 
Figura 1. Comparação entre gêneros no Assentamento "Abrindo Fronteiras" e no Brasil

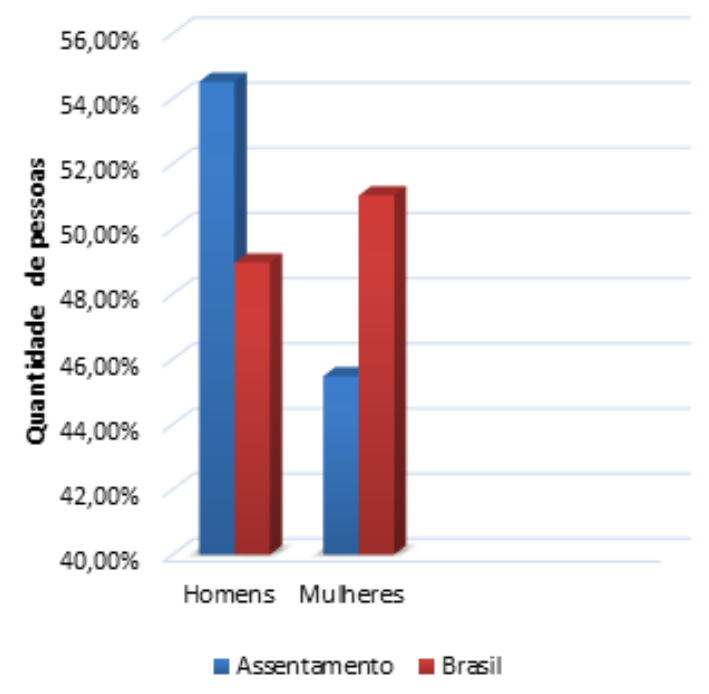

Apenas 41 pessoas possuem ensino superior, o nível de escolaridade encontrado é baixo, mas a grande maioria possui algum grau de alfabetização. Ainda existe uma contradição entre o termo analfabetismo. No assentamento é quase nulo o número de analfabetos rudimentares, aqueles sem nenhum grau de compreensão alfabética. $\mathrm{O}$ que se encontra são pessoas consideradas analfabetas funcionais, conforme a definição da UNESCO. Uma das principais medidas da determinação da população analfabeta funcional é a forma indireta, que considera os indivíduos com 15 anos ou mais que náo tenham concluído mais de quatro anos completos de estudo.

Um dos parâmetros utilizados para definir a agricultura familiar é o tipo de mão de obra utilizada. Sendo que o levantamento neste assentamento mostra a predominância de pessoas que possuem a agricultura como ocupação principal e vivem com essa renda. Isso mostra um grande potencial de força de trabalho, essencial para o crescimento da agricultura. A maioria da produção é para autoconsumo, mas é relevante a quantidade processada de leite para fabricação de queijo e processamento da cana-deaçúcar para cachaça. Atualmente, existe um projeto em andamento para construçáo de uma agroindústria familiar para a fabricação de queijos, o que é essencial para regulamentar a condição sanitária do produto destinado à venda.
Na produção agrícola, 95\% utiliza a maneira de preparo do solo convencional e 44\% sem adubação. Os cultivos não são tratados com pesticidas por falta de dinheiro para investir na produção já que é muito difícil a liberação de financiamentos, pois a maioria náo possui crédito, desse modo $86 \%$ dos produtores afirmam não usar nem um tipo de pesticida. Ganha destaque a produção de sementes de abóbora e de milho. O milho que é predominante é em sua maioria destinado para o uso como ração animal para a bovinocultura de leite, cultivado em 1721 hectares. Rebanhos de bovinos de corte também são comuns e sua destinação principal é a carne para autoconsumo, seguido da criação de suínos e ovinos. 72 famílias utilizam a produção de carne para consumo próprio. Outras atividades como piscicultura e apicultura já foram importantes, mas atualmente estão extintas.

Quando verificadas as questôes de moradia, todos as possuem. A maioria das construçóes é em alvenaria e madeira, mas existem casos em que as moradias são anexas aos galpóes agrícolas. Um fator preocupante diz respeito às condiçôes sanitárias encontradas. A água consumida é vinda de um poço comum ou de captação com armazenamento em caixas de água. As condiçóes de limpeza das caixas e tratamentos da água são precárias e quase $80 \%$ das famílias indicam consumir água de baixa qualidade, além de ainda existir lotes que não possuem água no local, como mostra a Figura 2.

Figura 2. Formas de consumo de água encontradas no Assentamento "Abrindo Fronteiras"

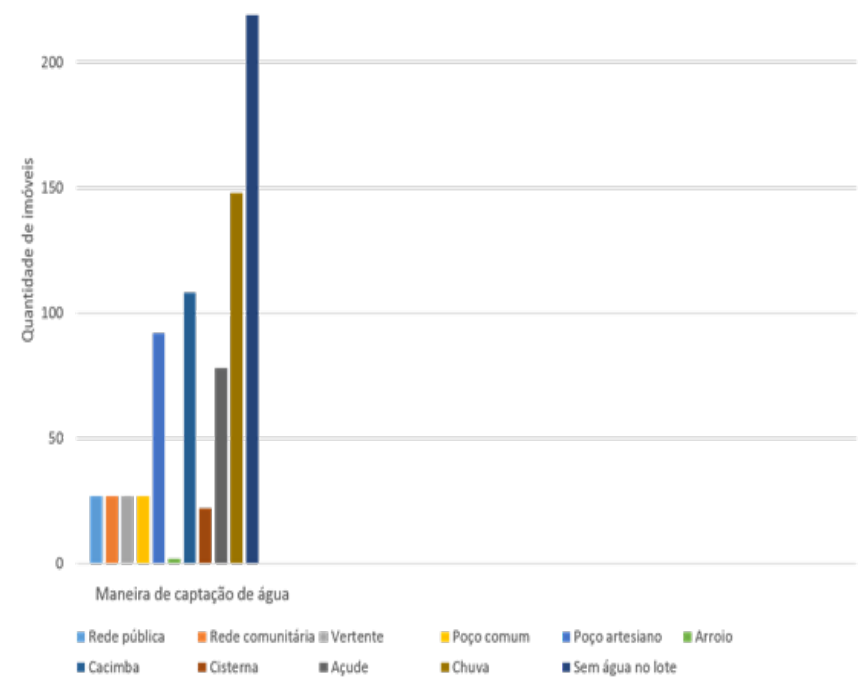


Um indicador importante de contaminação da água é a falta de esgoto sanitário. É alarmante a quantidade de despejo a céu aberto encontrado. Uma parte ainda conta com fossas sépticas e sumidouros, porém apenas três caixas sépticas com tratamento ecológico foram encontradas. Esta última, sendo a maneira ideal de descarte de esgoto é a menos utilizada.

O plano de saneamento do local não é funcional, burlando a lei de crime ambiental número 9605, de 1998, que proíbe a queimada de resíduo domiciliar de natureza vegetal ou qualquer outro tipo de resíduo, pois constatou-se que a maioria do lixo produzido é queimado. Não existe plano de coleta seletiva pública.

As problemáticas condições ambientais e sanitárias levaram à iniciativa de uma proposta de fossa séptica caseira acessível aos moradores, conforme mostra a Figura 3 e a intenção de um plano de desenvolvimento no destino do lixo gerado.

Figura 3. Parte do manual de construção de fossa séptica sustentável
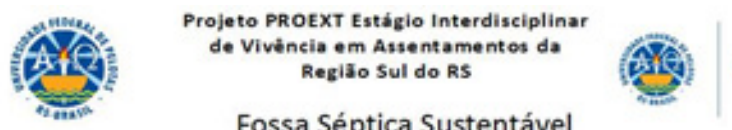

UFPEL

Fossa Séptica Sustentável

- o que e a fossa séptica sustentável?

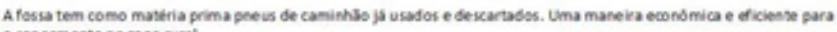
0 sanesmetent

- como funciona a fossa séptica?

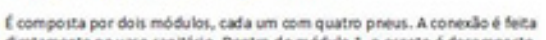

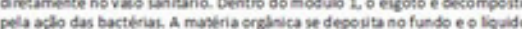

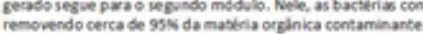

-ApRenda a fazer a fossa séptica EM SUA PRopriedade. Materias necessarios para construer vma foss com capacidade para asender a uma moradia com att quatro pessoss.

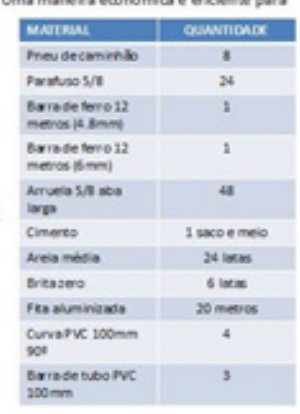

Com as visitas foi possível observar que o hábito de uma alimentação mais saudável não era adotado por essas famílias e a criação de hortas faria a diferença nessa realidade. Devido a isso,como forma de incentivo ao consumo de hortaliças, foi realizado um folder orientando as famílias a realizar uma horta de simples construção com a utilização de materiais baratos e de fácil acesso (Figura 4).

Figura 4. Parte do manual de construção de horta familiar

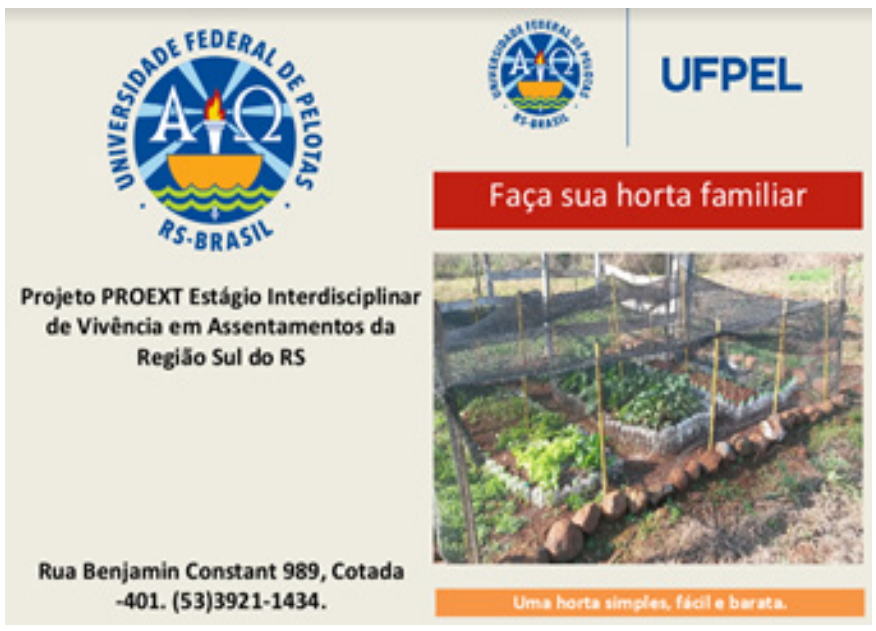

Além da distribuição do folder com o incentivo da construção da horta, foi realizada uma entrega de cem mudas de araçá aos assentados. O araçá (Psidium cattleianum) é uma planta nativa da regiáo, rica em vitaminas $\mathrm{A}, \mathrm{B}, \mathrm{C}$, antioxidantes, carboidratos e proteínas, ferro, cálcio e fósforo. Possui alto potencial no tratamento de enfermidades e diversidades de receitas, podendo ser usado em forma de suco, na criação de sorvetes, doces e geleias.

As mudas foram doadas pelo Programa de Pósgraduação em Agronomia com concentração em Fruticultura. Posteriormente, foi criado um manual de cultivo de araçá, conforme a Figura 5, para ser distribuído para os moradores, a fim de dar auxílio no cultivo das mudas recebidas.

Figura 5. Parte do Manual de cultivo de araçá

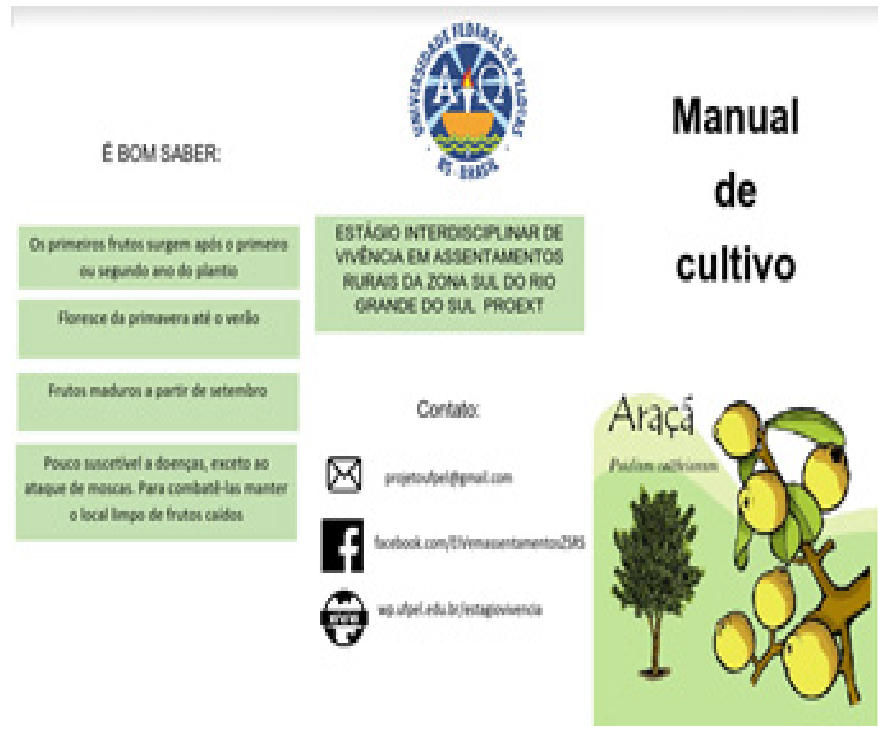


Em suma, pode-se concluir que esses pequenos agricultores quando recebem seu lote de terra para habitar e gerar seu sustento permanecem passando por dificuldades para mantê-lo, e é aí que o estágio de vivência pode ser crucial para a melhoria de vida destas pessoas. O projeto de Estágio de Vivência Interdisciplinar em Assentamentos da Zona Sul do Rio Grande do Sul é uma troca, onde os alunos participantes doam suas aptidóes obtidas dentro das salas de aula para o desenvolvimento de recursos em prol do assentado. Em troca é proporcionado a este uma instrução não recebida durante a sua graduação e que os próprios assentados lhes cedem seus saberes adquiridos durante a vida toda por meio da vivência no meio rural. $\mathrm{O}$ aluno também tem a oportunidade de pôr em prática tudo que aprendeu na universidade. Tem a chance de conviver com uma realidade social, política, econômica e cultural diferente da sua, o que pode gerar uma visão mais crítica da sociedade. E por fim, ganha a experiência de trabalhar com outras áreas, com pessoas diferentes e assim se tornar um profissional mais qualificado, mas também um indivíduo com moral e princípios que se preocupa com o próximo.

\section{CONCLUSÃO}

O levantamento realizado demonstrou a necessidade de intervenção e suporte aos moradores do Assentamento Abrindo Fronteiras, principalmente nos quesitos alimentares e de saneamento.

A troca vivida por esse aluno participante do estágio transforma o mesmo em um ser mais crítico e o proporciona a pensar em soluçóes, cuja técnica aprendeu em sala de aula.

\section{LITERATURA CITADA}

CAPORAL, F. R. Superando a revolução verde: a transição agroecológica no RS. Agroecologia e Desenvolvimento Rural Sustentável, v. 3, n. 3, p 70-85, 2002.

IBGE. Instituto Brasileiro de Geografia e Estatística. "Cidades". 2016. Disponível em: <http://www.cidades.ibge.gov.br/painel/ historico.php?lang=\&codmun $=430965 \&$ search $=\% 7$ Chulhanegra>. Acesso em: 20 out. 2016.

INCRA. Instituto Nacional de Colonização e Reforma Agrária. "Assentamentos". 2016. Disponível em:<http://www.incra.gov. br/assentamento>. Acesso em: 20 out. 2016.

LORENZO, C. O consentimento livre e esclarecido e a realidade do analfabetismo funcional no Brasil: uma abordagem para a norma e para além da norma. Revista Bioética, v.15, p.268-282, 2007.

MENEZES, Renata de Castro. A dinâmica do Sagrado: rituais, sociabilidade e santidade num convento no Rio de Janeiro. Rio de Janeiro: Relume Dumará, NUAP, 2004. 